\title{
Differences in asthma management between white European and Indian subcontinent ethnic groups living in socioeconomically deprived areas in the Birmingham (UK) conurbation
}

\author{
H Moudgil, D Honeybourne
}

\begin{abstract}
Background-Hospital admission rates for asthma have been higher for Asian (Indian subcontinent, ISC) ethnic minority groups in the UK than for white Europeans (W/E). As this may in part be due to differences in the uptake or delivery of preventative health care strategies, the extent to which targeted education and treatment programmes reach these groups needs to be determined.

Methods-Six hundred and eighty nine asthmatic subjects ( $345 \mathrm{~W} / \mathrm{E}, 344$ ISC) of mean (SD) age 34.5 (15) years (range 11-59) and mean forced expiratory volume in one second $\left(\mathrm{FEV}_{1}\right) \mathbf{8 0 \%}$ predicted from districts of high ethnicity and socioeconomic deprivation within inner city Birmingham were reviewed in the appropriate dialect (English, Punjabi, Hindi, Urdu) in a community based study.

Results-Data adjusted for age and ana-
\end{abstract} lysed separately for men $(M)$ and women (F) showed no significant differences in the numbers reporting previous asthma education, assessment of delivery techniques, or being taught about medications, but there were significant differences for advice on trigger factors (M: $52 \%$ vs $42 \%$; F: $56 \%$ vs $42 \%$ ), recognition of symptoms (M: $51 \%$ vs $43 \%$; F: $53 \%$ vs $33 \%$, and ownership of peak flow meters (M: $35 \%$ vs $22 \%$; F: $36 \%$ vs $24 \%$ ) for W/E and ISC groups, respectively. Antiinflammatory asthma medications were highly prescribed, but self reported drug compliance (M: $73 \%$ vs $62 \%$ ), understanding medications (F: $59 \%$ vs $39 \%$ ), and self management (F: $23 \%$ vs $12 \%$ ) varied significantly. Asthma follow up in the community was low for both groups with more of the ISC subjects also being followed up by hospital.

Conclusions-The management of both ethnic groups has centred on drug prescription, delivery techniques and compliance, but has been deficient, particularly in the ISC group, in developing understanding of the disease and self management.

(Thorax 1998;53:490-494)

Keywords: asthma management; ethnic minority groups
Although inequalities in the delivery and uptake of preventative health care have frequently been implicated in the disproportionate asthma morbidity borne by socioeconomically deprived and ethnic minority groups, both in the UK and elsewhere, ${ }^{1-6}$ there are few data for these groups which specifically address their asthma knowledge or highlight ethnic differences in management. Such data could be valuable, particularly when planning health care strategies for some ethnic minority groups such as in the UK where, against a background of conflicting reports on asthma prevalence rates $^{7-9}$ but similar severity of acute episodes, higher hospital admission rates have been observed in Asian subjects (Indian subcontinent, ISC) than in white European (W/E) subjects. ${ }^{10-12}$ It is possible that, for the ISC group who frequently live in socioeconomically deprived inner city areas, the poor accessibility to preventative health care resulting from language or communication difficulties may further complicate variable cultural attitudes to asthma as a chronic disease or its management with prophylactic treatment. ${ }^{10-12}$

A study was undertaken from primary care registers to document the level of monitoring or follow up and preventative health care amongst W/E and ISC asthmatic subjects aged 11-59 years. This was part of a prospective community study based in districts of high ethnicity and medium or high socioeconomic deprivation in inner city Birmingham (UK). The study was designed to look for any differences in asthma management between the W/E and ISC ethnic groups by quantifying the extent of any targeted education and treatment programmes reaching these groups, and assessing the chronic nature of the disease or its severity using objective measures of airflow obstruction and current levels of drug prescription.

\section{Methods}

STUDY POPULATION

Birmingham has a population of approximately 1.1 million of whom $27.2 \%$ live in districts with medium or high socioeconomic deprivation (1991 National Jarman ${ }^{13}$ index >40). Information from the 1991 Office of Population Censuses and Surveys showed that ethnic minority groups, whether born in the UK or not, made up $21.5 \%$ of the population, were mainly ISC (representing most of the nonEnglish speaking) or black Afro-Caribbean (AFC), and that $57.3 \%$ lived in seven of the 
Table 1 Recruitment and subject characteristics

\begin{tabular}{|c|c|c|c|c|c|}
\hline & $W / E$ & & ISC & & $p$ value \\
\hline \multicolumn{6}{|c|}{ No. $(\%)$ of responders to study } \\
\hline Men & 154 & (43) & 183 & (67) & $<0.001$ \\
\hline Women & 191 & $(58)$ & 161 & $(71)$ & $<0.001$ \\
\hline \multicolumn{6}{|c|}{ No. (\%) smokers and ex-smokers } \\
\hline Men & 77 & $(50)$ & 63 & (34) & 0.298 \\
\hline Women & 102 & (53) & 8 & (5) & $<0.001$ \\
\hline \multicolumn{6}{|c|}{ Age (years) } \\
\hline Men & 34.7 & (15) & 29.7 & $(16)$ & 0.002 \\
\hline Women & 37.7 & (14) & 36.0 & (16) & 0.368 \\
\hline \multicolumn{6}{|c|}{ Age onset (years) } \\
\hline Men & 18.4 & (17) & 18.0 & (15) & 0.763 \\
\hline Women & 22.7 & (17) & 23.5 & (15) & 0.541 \\
\hline \multicolumn{6}{|c|}{ Mean (SD) $\mathrm{FEV}_{1}(\mathrm{l})$} \\
\hline Men & 2.91 & $(1.0)$ & 2.60 & $(0.8)$ & $<0.001$ \\
\hline \multirow{2}{*}{\multicolumn{6}{|c|}{ Mean (SD) \% predicted $\mathrm{FEV}_{1}$}} \\
\hline & & & & & \\
\hline Men & 76.9 & (22.4) & 81.9 & $(20.8)$ & 0.022 \\
\hline Women & 81.0 & $(21.8)$ & 78.1 & $(21.5)$ & 0.146 \\
\hline \multicolumn{6}{|c|}{ Mean (SD) peak flow (1/min) } \\
\hline Men & 439.3 & $(125.7)$ & 431.9 & $(113.1)$ & 0.195 \\
\hline Women & 355.2 & $(100.5)$ & 333.2 & $(93.3)$ & $<0.001$ \\
\hline \multicolumn{6}{|c|}{ Mean (SD) \% predicted peak flow } \\
\hline Men & 85.9 & $(22.1)$ & 92.7 & $(21.4)$ & 0.006 \\
\hline Women & 95.8 & (24.7) & 93.1 & (23.9) & 0.223 \\
\hline
\end{tabular}

$\mathrm{W} / \mathrm{E}=$ white European; $\mathrm{ISC}=$ Indian subcontinent $; \mathrm{FEV}_{1}=$ forced expiratory volume in one second.

Analysis adjusted for age with differences compared by Mantel-Haenszel $\chi^{2}$. p values of $<0.05$ considered significant. from the ISC group who could not communicate orally in English, Punjabi, Urdu, or Hindi were excluded. Permission for the study was obtained from the local ethics committee.

Demographic, socioeconomic, lifestyle, and illness profile data were collected but the focus of this study was primarily on asthma education and self management elements. Subjects were interviewed in their preferred language (as above) by the same researcher (HM) who read out questions in a structured way and recorded outcomes from free form responses. An objective confirmation of responses was sought and was possible for most aspects of self reported asthma knowledge including triggers, mechanisms and medications, but not for some other important aspects of management and, especially, the self reported drug compliance. In assessing asthma knowledge further clarification was necessary when determining whether subjects understood the role of their medications; they were considered knowledgeable if able to describe the appropriate "preventer" or "reliever" action of their medications and when to take them rather than simply being able to quote the terminology used.

Objective measures of airflow obstruction (by design at least six hours after the last bronchodilator) were made by mini Wright peak flow meter and a portable hand held spirometer (Medical International Research SPIROBANK) which also computed predicted values for sex, age, and height for white European subjects. ${ }^{15} \mathrm{~A}$ further adjustment with a $10 \%$ reduction in predicted values was made for the ISC ethnic group as recommended. ${ }^{16}$ Current levels of drug prescription were assessed against the 1993 British Thoracic Society (BTS) guidelines. ${ }^{17}$

\section{STATISTICAL ANALYSIS}

Descriptive and comparative analyses were made by standard computational methods using the Statistics Package for Social Sciences minority groups (mainly AFC and some mixed ethnicity) and a small number of asthmatics

Table 2 Uptake/delivery of preventative asthma care by men and women in the two ethnic groups

\begin{tabular}{llllll}
\hline & W/E no (\%) & ISC no (\%) & Crude OR & MHOR (95\% CI) & $p$ value \\
\hline Men & $\mathrm{n}=154$ & $\mathrm{n}=183$ & & & \\
$\quad$ Previous asthma education & $105(68)$ & $114(62)$ & 1.31 & $1.31(0.80$ to 2.15$)$ & 0.321 \\
Advised on trigger factors & $80(52)$ & $77(42)$ & 1.49 & $1.69(1.05$ to 2.75$)$ & 0.031 \\
Had symptoms/mechanisms explained & $79(51)$ & $79(43)$ & 2.45 & $2.46(1.58$ to 4.21$)$ & $<0.001$ \\
Had role of medications explained & $82(53)$ & $80(44)$ & 1.47 & $1.51(0.95$ to 2.43$)$ & 0.091 \\
Had drug delivery techniques assessed & $96(62)$ & $107(58)$ & 1.18 & $1.15(0.71$ to 1.87$)$ & 0.621 \\
On anti-inflammatory for asthma & $117(76)$ & $129(70)$ & 1.32 & $1.31(0.77$ to 2.28$)$ & 0.346 \\
Carries rescue $\beta_{2}$ agonists & $112(73)$ & $104(57)$ & 2.03 & $1.69(1.03$ to 2.87$)$ & 0.039 \\
Understands role of medications & $85(55)$ & $81(44)$ & 1.55 & $1.41(0.88$ to 2.28$)$ & 0.165 \\
Reports full drug compliance & $112(73)$ & $113(62)$ & 1.65 & $1.66(1.01$ to 2.80$)$ & 0.049 \\
Owns peak flow meter & $54(35)$ & $41(22)$ & 1.87 & $1.82(1.09$ to 3.09$)$ & 0.023 \\
Carries out self management & $27(18)$ & $21(11)$ & 1.54 & $1.41(0.70$ to 2.76$)$ & 0.404 \\
& & & & & \\
Women & $\mathrm{n}=191$ & $\mathrm{n}=161$ & & & \\
Previous asthma education & $134(70)$ & $109(67)$ & 1.12 & $1.22(0.75$ to 2.01$)$ & 0.471 \\
Advised on trigger factors & $107(56)$ & $67(42)$ & 1.79 & $1.99(1.27$ to 3.26$)$ & 0.003 \\
Had symptoms/mechanisms explained & $102(53)$ & $53(33)$ & 2.34 & $2.47(1.57$ to 4.03$)$ & $<0.001$ \\
Had role of medications explained & $98(51)$ & $78(48)$ & 1.12 & $1.22(0.77$ to 1.93$)$ & 0.438 \\
Had drug delivery techniques assessed & $123(64)$ & $99(61)$ & 1.13 & $1.24(0.78$ to 1.99$)$ & 0.404 \\
On anti-inflammatory for asthma & $155(81)$ & $128(80)$ & 1.11 & $1.12(0.62$ to 2.01$)$ & 0.795 \\
Carries rescue $\beta_{2}$ agonists & $161(84)$ & $118(73)$ & 1.96 & $2.18(1.22$ to 3.97$)$ & 0.008 \\
Understands role of medications & $112(59)$ & $62(39)$ & 2.26 & $2.27(1.44$ to 3.64$)$ & $<0.001$ \\
Reports full drug compliance & $142(74)$ & $108(67)$ & 1.42 & $1.48(0.90$ to 2.47$)$ & 0.127 \\
Owns peak flow meter & $68(36)$ & $38(24)$ & 1.95 & $2.11(1.27$ to 3.61$)$ & 0.004 \\
Carries out self management & $44(23)$ & $20(12)$ & 2.11 & $2.17(1.16$ to 4.09$)$ & 0.014 \\
\hline
\end{tabular}

$\mathrm{W} / \mathrm{E}=$ white European; ISC = Indian subcontinent; $\mathrm{MHOR}=$ odds ratio by the Mantel-Haenszel test; $\mathrm{CI}=\mathrm{Cornfield} 95 \%$ confidence intervals. $p$ values of $<0.05$ considered significant $\left(\mathrm{MH} \chi^{2}\right.$ test). 
Table 3 Previous emergency secondary health care and continuing follow up care in the two ethnic groups

\begin{tabular}{llllll}
\hline & W/E no (\%) & ISC no (\%) & Crude OR & MHOR (95\% CI) & $p$ value \\
\hline Men & $\mathrm{n}=154$ & $\mathrm{n}=183$ & & & \\
$\quad$ Asthma follow up by GP/nurse & $53(34)$ & $59(32)$ & 1.11 & $1.02(0.61$ to 1.69$)$ & 0.956 \\
Asthma follow up by hospital & $8(5)$ & $28(15)$ & 0.28 & $0.26(0.09$ to 0.78$)$ & 0.012 \\
$\quad$ Previous asthma admission & $44(29)$ & $50(27)$ & 1.06 & $0.97(0.57$ to 1.64$)$ & 0.986 \\
Previous A\&E attendance only & $25(16)$ & $22(12)$ & 1.42 & $1.45(0.73$ to 2.90$)$ & 0.333 \\
& & & & & \\
Women & $\mathrm{n}=191$ & $\mathrm{n}=161$ & & $0.89(0.56$ to 1.44$)$ & 0.709 \\
Asthma follow up by GP/nurse & $62(32)$ & $57(35)$ & 0.88 & $0.36(0.15$ to 0.86$)$ & 0.021 \\
Asthma follow up by hospital & $10(5)$ & $21(13)$ & 0.36 & $0.41(0.24$ to 0.67$)$ & $<0.001$ \\
Previous asthma admission & $39(20)$ & $64(40)$ & 0.42 & $0.91(0.50$ to 1.63$)$ & 0.823 \\
Previous A\&E attendance only & $32(17)$ & $30(19)$ & 0.87 & \\
\hline
\end{tabular}

$\mathrm{W} / \mathrm{E}=$ white European; ISC $=$ Indian subcontinent; $\mathrm{OR}=$ odds ratio; $\mathrm{MH}=$ Mantel-Haenszel. $\mathrm{CI}=\mathrm{Cornfield} 95 \%$ confidence intervals.

$\mathrm{p}$ values of $<0.05$ considered significant $\left(\mathrm{MH} \chi^{2}\right.$ test).

(SPSS/PC+ Base System) version 5.0 and Epi Info version 5 . Because of the age and sex differences between the comparative ethnic groups, categorical data were analysed separately for men (M) and women (F) comparing, when appropriate, by $\chi^{2}, \chi^{2}$ for linear trend, or Mantel-Haenszel (MH) summary $\chi^{2}$ stratified by six year age groups from 11 to 59 years. For important results specifically relating to asthma management, the crude odds ratios (OR) and the MH weighted odds ratios are quoted along with the Cornfield 95\% confidence intervals (CI). Reported $p$ values of $<0.05$ were considered statistically significant.

\section{Results}

Over a one year period to August 1996, 689 $(57 \%)$ of 1217 asthmatic subjects $(715 \mathrm{~W} / \mathrm{E}$, 502 ISC) attended for review; 345 of mean (SD) age 36.5 (15) years (range 11-59) were $\mathrm{W} / \mathrm{E}$ and 344 of mean age 32.6 (16) years (range 11-59) were from the ISC. Of the self defined ISC ethnic group, $144(42 \%)$ were non-UK born (mainly immigrants from the Indian subcontinent but also some from East and Central African countries), 117 (34\%) spoke no or very little English, and $31(9 \%)$ had never attended school. By contrast, $8 \%$ of the W/E group were non-UK born (mainly Irish) and all could speak English. There was a better response rate to the study from asthmatics who were slightly older with a mean (SD) age of 34.5 (15) vs 29.8 (13) years (p $<0.0001)$, from women than from men $(60.5 \%$ vs $53.1 \%, p=0.009)$, and from the ISC ethnic group than the W/E group ( $68.5 \%$ vs $48.3 \%$, p $<0.0001$ ).

Summary data characterising the W/E and ISC study subjects by sex and ethnic groups are shown in table 1 . The age at onset of disease was not significantly different between the two groups for either sex. More of the W/E group reported a smoking history with the difference being significant only for the women. Mean forced expiratory volume in one second $\left(\mathrm{FEV}_{1}\right)$ was $80 \%$ predicted for both groups when adjusted for factors including ethnicity ${ }^{15}$ and, when analysed separately, percentage predicted values for both $\mathrm{FEV}_{1}$ and peak flow were significantly lower for W/E men than for ISC men.

The uptake and delivery of different aspects of asthma health care and outcomes relating to knowledge and management are summarised in table 2. A moderately high percentage of asthmatic subjects from both ethnic groups and both sexes reported previous asthma education; for the ISC group this included 93/144 $(65 \%)$ of the non-UK born and $130 / 200$ $(65 \%)$ of the UK born asthmatics (OR 0.99, $95 \%$ CI 0.70 to $1.42, p=0.971)$. There was a considerable difference in mean (SD) age between English speaking and non-English ISC asthmatic subjects (23.3 (11.9) and 46.4 (10.0) years, respectively, $\mathrm{p}<0.0001)$. These groups were not compared directly in the analysis.

Specifically addressing educational content, a relatively high percentage from both ethnic groups reported assessment of delivery techniques, but fewer were taught about other aspects including medications and there were other significant differences between the groups with fewer in the ISC group being informed about trigger factors, mechanisms and recognition of symptoms, or prescribed peak flow meters. Significant differences were noted between the two groups (W/E > ISC) when considering self reported drug compliance (men), understanding the role of medications (women), and the level of self management initiatives (both sexes). When reanalysing only those subjects below 45 years of age $(63.2 \%$ of $\mathrm{W} / \mathrm{E}$ group and $70.6 \%$ of ISC group), the same differences between ethnic groups were found with the exception of carrying of rescue $\beta_{2}$ inhalers where the differences were no longer significant for either men $(\mathrm{p}=0.081)$ or women $(\mathrm{p}=0.084)$.

Comparing current levels of asthma prescriptions against the 1993 BTS steps showed that $95 \%$ of subjects of both sexes and from both ethnic groups were on steps 1 to 3 (full data not included) with the majority being prescribed anti-inflammatory asthma medications (usually inhaled corticosteroids) as in table 2 . Analysing all five steps for trends in prescribing, there were no significant differences between the two groups.

Emergency secondary health care during acute exacerbations of asthma and the current use of primary and secondary health care preventative or follow up measures are summarised in table 3. There were no significant differences between the two groups for either sex in relation to previous attendance at accident and emergency (A\&E) departments. When previous asthma related admissions in the two groups were compared there was a significant difference amongst the women (ISC > 
$\mathrm{W} / \mathrm{E})$ but not the men in reporting at least one previous admission. Although the community follow up (GP/nurse) specifically for asthma was low and not significantly different between ethnic groups, significantly more of the ISC subjects (both sexes) were currently being followed up by hospitals.

\section{Discussion}

This study has provided new data identifying the level of uptake and delivery of preventative health care specific to $\mathrm{W} / \mathrm{E}$ and ISC asthmatic subjects living in the same areas of high ethnicity and socioeconomic deprivation. By studying asthmatics in the community, we are able to report on subjects across the whole range of severity of asthma and, similarly, by addressing the ISC ethnic group in the patient preferred dialect we have shown important ethnic differences in asthma management. A large percentage of the ISC group were non-UK born and non-English speaking, but a similar proportion of the UK born ISC group (not adjusted for age or sex) reported previous asthma education. More specifically, although similar proportions in both groups reported receiving asthma education, the recognition of trigger factors and symptoms and subsequent self management skills differed significantly.

The low uptake among ethnic minority groups of some screening and preventative health care strategies, ${ }^{18}$ as well as the higher rates of drug prescription, ${ }^{19}$ may in part result from differing attitudes to disease and its management or compliance with prophylactic medications, as well as representing difficulties in communication. Language barriers cannot be overlooked in a condition such as asthma where patient education ${ }^{20-22}$ and preventative measures $^{23}$ have been shown to make an impact. Our previous postal questionnaire ${ }^{24}$ with a $68.5 \%$ response rate to assess the development of primary care asthma provisions in all areas of Birmingham in 1995 highlighted that, in responding general practices with exclusively Caucasian doctors or nurses, only 14 of $72(19.4 \%)$ had interpreters (usually other non-medical staff) to help overcome language barriers. However, as many inner city ISC groups traditionally register with practices whose doctors and/or nurses are able to communicate in the same patient preferred language, or attend with family or friends able to translate for them, the existing inequalities in asthma knowledge and management shown in this study may represent both a failure in delivery of educational preventative health care and the reduced uptake by patients because of continued language barriers.

Some of the elements of asthma management highlighted require further discussion. As this study has shown differences in the content of what is actually being taught, more attention should be paid to content when developing future asthma education programmes and consideration given to the format adopted. This study has found a greater emphasis for both ethnic groups on achieving appropriate prescription and assessment of delivery techniques, both of which have previously been shown to make a difference, and this compares with the lower levels of self management initiatives where the benefits in all except the very severe asthmatics are uncertain. ${ }^{25}$ Additionally, although patients like to be informed about self management, it is suggested that many do not want to take full responsibility for their condition, particularly when ill, ${ }^{26}$ and their knowledge can only at best be a guide to subsequent behaviour. In addition to economic status and literacy level which may prove to be barriers to education, ${ }^{27}$ studies have also shown that psychological and interpersonal problems and attitudes to their doctor's advice affect how well asthmatic patients follow medical advice. ${ }^{28}$

The measures of lung function reported here are probably as expected in the community where most asthmatic subjects are said to have mild to moderate disease. The higher percentage predicted $\mathrm{FEV}_{1}$ for the men in the ISC group is to be expected as proportionately more of the $\mathrm{W} / \mathrm{E}$ subjects reported a previous smoking history. Importantly, however, the percentage predicted $\mathrm{FEV}_{1}$ for the women in both groups was not significantly different, which is more surprising as $95 \%$ of the women in the ISC group were never smokers; chronic poor control of inflammation in the airways may be a contributory factor in these women and this is also suggested historically as more of them reported previous asthma related hospital admissions.

Similar proportions from both ethnic groups were being followed up in the community but significantly more of the ISC group were followed up by hospitals. It may be argued that the lower hospital follow up of the W/E group represented a better discrimination than in the community between the subjects who may have chronic bronchitis rather than asthma, particularly in view of the reported smoking association; however, against this suggestion is possibly the relatively preserved lung function as assessed by percentage predicted values for $\mathrm{FEV}_{1}$ or peak flow. Additionally, the current level (BTS steps) of asthma medications, which may be a surrogate measure of disease severity, did not differ between the two groups. Although we have reported previous hospital admissions and attendance at A\&E departments, this refers to events over the duration of the disease rather than an incidence rate and does not attempt to quantify differentially for re-admissions or multiple attendance. Hospital admissions from socioeconomically deprived areas are more likely to be directly via presentation at the $\mathrm{A} \& \mathrm{E}$ department than referral by the general practitioner. ${ }^{1}$

We recognise that the methods used in this study are open to response bias and in, the comparative analysis of data, have attempted to adjust for age and sex differences, but have not specifically allowed for differences between ethnic groups in reported smoking history or for the better response rate to the study by the ISC group. With respect to the latter, however, subsequent replies to a postal questionnaire from those who failed to attend this study ${ }^{29}$ suggested that most had continuing self 
reported asthma morbidity (symptoms) with similar levels in the two ethnic groups.

This study has been restricted to the 11-59 year age group and may fail to detect important differences at the extremes of age. This may be relevant for younger children where reported admission rates have risen most dramatically ${ }^{30}$ and for whom asthma prevalence rates are most frequently reported, ${ }^{7-9}$ as well as for the older age groups where the language and cultural differences may be expected to have a greater impact. By design we opted for the lower age cut off of 11 years as this was considered an appropriate age after which study subjects could reasonably be expected to respond independently to direct questioning about their asthma history or management. The upper age cut off of 59 years was set in an attempt to avoid diagnostic transfer from other forms of airflow obstruction, but in view of the high percentage reporting a smoking history and any concern about diagnostic transfer, even at this age limit, results from table 1 were re-analysed for subjects aged below 45 years and confirmed almost the same differences between ethnic groups.

Thus, by comparing the management of the indigenous W/E group with that of an ISC group from the same districts of socioeconomic deprivation, we have been able to define differences specifically due to ethnicity. Whilst the study did not specifically examine the reported ${ }^{1}$ strong association between deprivation and continued morbidity from asthma, some of the results presented here for both ethnic groups, including the differences highlighted, may be specific to deprived areas. A relatively high percentage from both groups reported previous asthma assessment and education, but with more emphasis on appropriate prescription, delivery techniques, and compliance rather than developing patient knowledge on actual symptom recognition, role of the medications, and self management initiatives. Many of these features were more noticeably lacking for the ISC group (both sexes) and probably represent a failure of delivery and patient uptake of preventative health care. As previously suggested, cultural attitudes ${ }^{10-12}$ and the differing educational and language skills may be contributory. Which of the inequalities in asthma management shown directly influences admission rates or can be specifically addressed by educational programmes based in the relevant ethnic dialect requires further assessment by prospective intervention studies. In addition, whether any of the findings can be more generalised to ethnic minority populations elsewhere also requires continued research.

\footnotetext{
We acknowledge advice on statistical analysis from Dr Paul
Davies at the Department of Mathematics, University of Davies at the Department of Mathematics, University of
Birmingham. We especially recognise the efforts and support of Birmingham. We especially recognise the efforts and support of all the patients and staff associated with participating general
practices and, in particular, Dr Abrol (City Road Medical Pracpractices and, in particular, Dr Abrol (City Road Medical Prac-
tice), Dr Adak (Rookery Road), Dr Bansel (Grove Lane and tice), Dr Adak (Rookery Road), Dr Bansel (Grove Lane and
Firs Lane), Dr Childs (Cape Hill Medical Centre), Dr Forrest Firs Lane), Dr Childs (Cape Hill Medical Centre), Dr Forrest
(Karis Medical Centre), Dr Joshi (Aston Health Centre), Dr (Karis Medical Centre), Dr Joshi (Aston Health Centre), Dr
Mukherjee (Newtown Health Centre), Dr Saini (Soho Health Centre), Dr Sharma (Handsworth Medical Practice), D Thompson (Soho Health Centre), and Dr Venugopal (Aston Health Centre). We acknowledge financial support for the project from the former West Midlands Regional Health Authority and North Birmingham Health Authority. We also
}

acknowledge Allen \& Hanburys (Glaxo/Wellcome) for their provision of patient asthma education literature and the generous support of peak flow meters donated by Astra Pharmaceuticals, Vitalograph and, in particular, Mr John Cummings on behalf of Ferraris Medical.

1 Watson JP, Cowen P, Lewis RA. The relationship between sthma admission rates, routes of admission, and socioeconomic deprivation. Eur Respir F 1996;9:2087-93.

2 Walters S, Phupinyokul M, Ayres J. Hospital admission rates for asthma and respiratory disease in the West Midlands: their relationship to air pollution levels. Thorax 1995;50: 948-54.

3 De Palo VA, Mayo PH, Frieman P, et al. Demographic influences on asthma hospital asdmission rates. Chest 1994; 106: $447-51$.

4 Gottlieb DJ, Beiser AS, O’Connor GT. Poverty, race, and medication use are correlates of asthma hospitalisation rates. A small area analysis in Boston. Chest 1995;108:2835 .

5 Carr W, Zeitel L, Weiss K. Variations in asthma hospitalizations and deaths in New York City. Am $\mathcal{f}$ Public Health $1992 ; 82: 59-65$.

6 Robson B, Woodman K, Burgess C, et al. Prevalence of asthma symptoms among adolescents in the Wellington region, by area and ethnicity. $N Z$ Med f 1993;106:239-41.

7 Smith JM, Cooper SM. Asthma and atopic disease in immigrants from Asia and the West Indies. Postgrad Med F 1981; 57:774-6.

8 Johnston IDA, Bland JM, Anderson HR. Ethnic variation in respiratory morbidity and lung function in children. Thorax 1987;42:542-8

9 Pararajasingham C D, Sittampalam L, Samani P, et al. Comparison of the prevalence of asthma among Asian and European children in Southampton. Thorax 1992;47:52932.

10 Ormerod LP. Adult Asian acute asthma admissions reassessed: Blackburn 1991-1992. Respir Med 1995;89: 415-7.

11 Ayres JG. Acute asthma in Asian patients: hospital admissions and duration of stay in a district with a high immigrant population. Br f Dis Chest 1986;80:242-8.

12 Myers P, Ormerod LP. Increased asthma admission rates in Asian patients: Blackburn 1987. Respir Med 1992;86:297300.

13 Jarman B. Identification of underprivileged areas. BMF 1983;286:1705-9.

141991 Census Topic Reports: Ethnic Groups in Birmingham. Birmingham City Council.

15 Quanjer $\mathrm{PhH}$. Standardised lung function testing. Report of Working Party for the European Community for Steel and Coal. Bull Eur Physiopathol Respir 1983;19(Suppl 15).

16 Quanjer $\mathrm{PhH}$, ed. Standardisation of lung function tests, 1993. Update of Report of Working Party for the European Community for Steel and Coal. Eur Respir f 1993;6(Suppl 16).

17 British Thoracic Society (BTS). Guidelines on the management of asthma. Thorax 1993;48(Suppl):S1-24.

18 Atri J, Falshaw M, Livingstone A, for Healthy Eastenders Project. Fair shares in health care? Ethnic and socioeconomic influences on recording of preventative care in selected inner London general practices. BMf 1996;312: 614-7.

19 Gill P, Scrivener G, Lloyd D, et al. The effect of ethnicity on prescribing rates. Health Trends 1995;27:111-4

20 Garrett J, Fenwick J M, Taylor G, et al. Prospective controlled evaluation of the effect of a community based asthma education centre in a multiracial working class neighbourhood. Thorax 1994;49:976-83.

21 Lahdensuo A, Haahtela T, Herrala J, et al. Randomised comparison of guided self management and traditional treatment of asthma over one year. BMF 1996;312:748-52.

22 Kelso TM, Self TH, Rumbak MJ, et al. Educational and long -term therapeutic intervention in the ED: effect on outcomes in adult indigent minority asthmatics. $A m \mathcal{F}$ Emerg Med 1995;13:632-7.

23 Horn CR, Clark TJH, Cochrane GM. Can the morbidity of asthma be reduced by high dose inhaled therapy? A prospective trial. Thorax 1988;43:252.

24 Moudgil H, Cunningham B, Honeybourne D. Primary care asthma: developments in the Birmingham (UK) conurbation and the role of the practice nurse. Eur Respir f 1996;9: $223-4 \mathrm{~s}$

25 Jones KP, Mullee MA, Middleton M, et al. Peak flow based asthma self-management: a randomised controlled study in general practice. British Thoracic Research Committee. Thorax 1995;50:851-7.

26 Gibson PG, Talbot PI, Toneguzzi RC. Self-management, autonomy, and quality of life in asthma. Population Medicine Group 91C. Chest 1995;107:1003-8.

27 Fitzgerald JM. Psychological barriers to asthma education. Chest 1994;106:2605-35.

28 Bosley CM, Parry DT, Cochrane GM. Patient compliance with inhaled medication: does combining beta-agonists with corticostero

29 Moudgil H, Cunningham B, Honeybourne D. Uptake of preventative health care strategies in asthma: defining nonattenders. Eur Respir f 1997;10(Suppl 25):446s.

30 Anderson HR. Increase in hospital admissions for childhood asthma: trends in referral, severity, and re-admissions from 1970 to 1985 in a health region of the United Kingdom. Thorax 1989;44:614-9. 